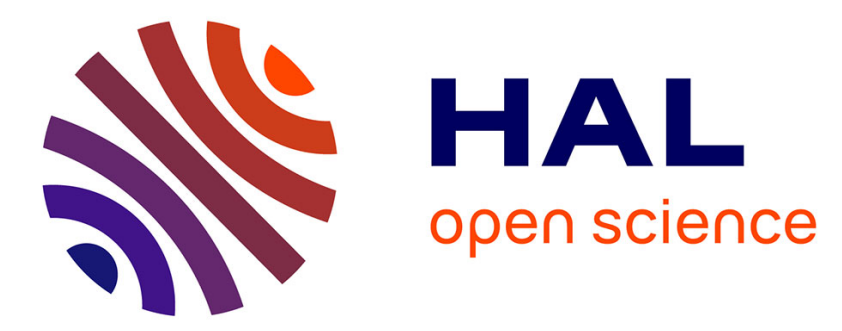

\title{
Supramolecular assemblies of 1,4-benzene diboronic acid on $\mathrm{KCl}(001)$
}

Rémy Pawlak, Laurent Nony, Franck Bocquet, Vincent Oison, Michel Sassi, Jean-Marc Debierre, Christian Loppacher, Louis Porte

\section{- To cite this version:}

Rémy Pawlak, Laurent Nony, Franck Bocquet, Vincent Oison, Michel Sassi, et al.. Supramolecular assemblies of 1,4-benzene diboronic acid on $\mathrm{KCl}(001)$. Journal of Physical Chemistry C, 2010, 114, pp.9290-9295. 10.1021/jp102044u . hal-00487054

\section{HAL Id: hal-00487054 \\ https://hal.science/hal-00487054}

Submitted on 29 May 2010

HAL is a multi-disciplinary open access archive for the deposit and dissemination of scientific research documents, whether they are published or not. The documents may come from teaching and research institutions in France or abroad, or from public or private research centers.
L'archive ouverte pluridisciplinaire HAL, est destinée au dépôt et à la diffusion de documents scientifiques de niveau recherche, publiés ou non, émanant des établissements d'enseignement et de recherche français ou étrangers, des laboratoires publics ou privés. 


\section{Supramolecular assemblies of 1,4-benzene diboronic acid on $\mathrm{KCl}(001)$}

Rémy Pawlak, Laurent Nony, ${ }^{*}$ Franck Bocquet, Vincent Oison, Michel Sassi, Jean-Marc Debierre, Christian Loppacher, and Louis Porte

Aix-Marseille University, IM2NP, Av. Normandie-Niemen, Case 151, F-13397 Marseille CEDEX 20, France

and CNRS, IM2NP (UMR 6242), Marseille-Toulon, France

E-mail: laurent.nony@im2np.fr;Phone:+33491288997;Fax:+33491288775

Published in J. Phys. Chem. C 2010, 114, 9290-9295

${ }^{*}$ To whom correspondence should be addressed 


\begin{abstract}
The self-assembly of benzene diboronic acid molecules on $\mathrm{KCl}(001)$ is investigated at room temperature by means of non-contact Atomic Force Microscopy. When depositing the molecules on the freshly cleaved surface, the molecules self-assemble into an extended twodimensional supramolecular phase driven by H-bonds. Theoretical calculations based on Density Functional Theory show that the cohesion energy of the structure yields almost $1 \mathrm{eV}$ per molecule. In combination with high-resolution structural analysis of the molecular layer and theoretical calculations, it is inferred that the growth of the supramolecular phase is made possible owing to the conformational adaptation of the molecule at the surface, which strengthens the intermolecular H-bonds, while avoiding the intermolecular steric hindrance. This work is the first experimental evidence of an extended H-bonded supramolecular network grown on a bulk insulator at room temperature.
\end{abstract}




\section{Introduction}

Over the past decade, supramolecular engineering of organic molecules on metallic surfaces, essentially $\mathrm{Au}, \mathrm{Cu}$ and $\mathrm{Ag}$, has achieved a high level of control for the growth of structurally complex self-assemblies with low-dimensionality (1D or 2D), specific shape, homo- or heteromolecular composition and functional properties. ${ }^{1,2}$ Most of the time, these molecular phases rely on supramolecular chemistry concepts, ${ }^{3,4}$ for which bonds between molecules, so-called tectons, have a non-covalent character. As discussed in details in ref. ${ }^{1}$, these interactions notably gather selective and directional Hydrogen-bonding interactions (energy barrier: 0.05-1 eV) and nonselective van der Waals ones $(0.02-0.1 \mathrm{eV})$. On metallic surfaces, the current trend is to tailor the growth of more robust organic networks as evidenced by recent approaches such as metalinduced catalysis, ${ }^{5,6}$ improved H-bonds by temperature-activated dehydrogenation ${ }^{7}$ and covalent polymerization of the tectons performed directly at the surface. ${ }^{8-13}$

Conversely, the growth of extended molecular networks based on supramolecular chemistry concepts have not really bridged the gap towards surfaces of bulk insulators yet. Owing to their wide optical band gap, these bear promise for technological applications though, notably in optoelectronics. ${ }^{14,15}$ Furthermore, it is now well-stated that even in the case of ultra-thin insulating films on metals, the insulating layer allows for efficient electronic decoupling between the molecular layer and the surface states of the metal, hence preserving the intrinsic properties of the molecules and avoiding optical quenching. ${ }^{16-19}$ On metallic surfaces, the growth of supramolecular networks is made possible by the overall favorable balance between lateral diffusion, adsorption energy, intermolecular interactions and, in most cases, planar adsorption of the tectons. The less reactive surfaces of bulk insulators significantly modify the parameters of this balance, which makes the growth of well-extended monolayers challenging, particularly at room temperature. For instance, recently, Bombis et al. have obtained extended $\mathrm{H}$-bonded molecular structures on a $\mathrm{NaCl}$ thin film in epitaxy on $\mathrm{Au}(111)$ by depositing melamine and cyanuric acid molecules that were merely stable up to $160 \mathrm{~K} .^{20}$

When dealing with bulk insulating samples, the atomic- and molecular-scale analysis is to 
be performed by means of non-contact atomic force microscopy (nc-AFM) under ultra-high vacuum (UHV) conditions. The surfaces of ionic single crystals such as $\mathrm{NaCl}(001), \mathrm{KCl}(001)$ and $\mathrm{KBr}(001)$, are prototypical insulating surfaces for the deposition of organic molecules. With these surfaces, perylene-derivatives (3,4,9,10-perylene tetracarboxylic dianhydride (PTCDA), ${ }^{1521-27}$ N,N'dimethylperylene-3,4,9,10-bis(dicarboximide) $\left.{ }^{28,29}\right), \mathrm{C}_{60},{ }^{24,30-32}$ porphyrins-derivatives (Cu-tetra[3,5di-tert-butylphenyl]porphyrin, ${ }^{21}$ meso-(4-cyanophenyl)-substituted Zn(II) porphyrin ${ }^{33-35}$ ) and phtalocyanines-derivatives $^{36}$ have been investigated. Among these, PTCDA is the most prominent example of well-ordered and extended network in the sub-monolayer regime. The epitaxial growth of two-dimensional islands of PTCDA has been reported at room temperature on $\mathrm{KCl}(001)^{14}$ and on $\mathrm{NaCl}(001),{ }^{26}$ resulting in two structurally distinct phases that also differ from the well-known herringbone structure found in the molecular crystal. On both surfaces, the epitaxial growth of the molecules is driven by van der Waals (vdW) and electrostatic (ES) interactions between each molecule and the substrate $(\mathrm{vdW} \simeq 0.82 \mathrm{eV}, \mathrm{ES} \simeq 1 \mathrm{eV}) .{ }^{37}$ The resulting intermolecular interactions, of same nature, are about a third weaker. This example shows that the growth of molecular structures on insulating surfaces is possible, but is driven by a delicate balance between moleculesubstrate interactions vs. intermolecular interactions. Thus, the growth of extended and robust supramolecular phases on insulating surfaces requires intermolecular interactions with an energy range going beyond vdW interactions.

Boronic acids have a wide range of applications, e.g. in medicine, ${ }^{38}$ analytical chemistry ${ }^{39}$ and nonlinear optics. ${ }^{40,41}$ The molecule of 1,4-benzenediboronic acid (BDBA, Scheme 1a) contains four hydroxyl groups, which enables the formation of hydrogen- or coordinative-bonds, ${ }^{39,42,43}$ and two boron atoms with a Lewis acid character. The most stable configuration of the isolated molecule that was derived from DFT calculations, is shown in Scheme 1a (details of the calculations are given in the next section). The molecule adopts a planar configuration with hydroxyl groups of both $\mathrm{B}(\mathrm{OH})_{2}$ groups lying in the same plane as the phenylene cycle. In the molecular crystal, BDBA molecules stack to form a lamellar structure with a triclinic unit cell including a single molecule. The structure has been characterized in details and calculated by Cuamatzi et al. 
in ref. ${ }^{42}$. We have derived the 3D structure of the crystal by DFT calculations as well. It is shown in Scheme $1 \mathrm{~b}$ and is found to be consistent with the one reported by Cuamatzi et al.: $\mathrm{a}=4.989 \AA$; $\mathrm{b}=5.305 \AA ; \mathrm{c}=7.368 \AA ; \alpha=93.797^{\circ} ; \beta=104.429^{\circ} ; \gamma=97.886^{\circ}$. The crystal consists of molecular sheets forming the plane defined by $\vec{a}$ and $(\vec{c}-\vec{b})$ that stack along the $\vec{c}$ axis. The sheets weakly interact by vdW interactions and are separated by about $0.37 \mathrm{~nm}$. Within each sheet, the molecules are linked by two kinds of $\mathrm{H}$-bonds between $\mathrm{B}(\mathrm{OH})_{2}$ groups. Primary intermolecular association involves the formation of the homodimeric $\mathrm{B}(\mathrm{OH})_{2} \ldots(\mathrm{HO})_{2} \mathrm{~B}$ motif along the $(\vec{c}-\vec{b})$ axis $\left(\mathrm{O}_{B} \mathrm{H}_{B} \ldots \mathrm{O}_{C}\right.$ and $\mathrm{O}_{D} \mathrm{H}_{D} \ldots \mathrm{O}_{A}$ bonds between molecules $\mathrm{B} / \mathrm{C}$ and $\mathrm{D} / \mathrm{A}$ in Scheme $1 \mathrm{~b}$, respectively). These associate by secondary $\mathrm{H}$-bonds along the $\vec{a}$ axis to form sheets $\left(\mathrm{O}_{A} \mathrm{H}_{A} \ldots \mathrm{O}_{B}\right.$ and $\mathrm{O}_{C} \mathrm{H}_{C} \ldots \mathrm{O}_{D}$ bonds between molecules $\mathrm{A} / \mathrm{B}$ and $\mathrm{C} / \mathrm{D}$, respectively). ${ }^{44,45}$ Besides, it has been recently put in evidence that BDBA molecules were able to polymerize in solution and form a 3D extended covalent organic framework $(\mathrm{COF}) .^{46,47}$ The polymer forms after dehydration of each molecule, thus allowing for the development of B-O-B intermolecular covalent bonds. Polymerization on $\mathrm{Ag}(111)$ at room temperature was also obtained to form a two-dimensional COF. ${ }^{9,48}$ Therefore, beyond its intrinsic optical properties, the ability of the molecule to develop H-bonds in the molecular crystal or to polymerize, makes it a suitable candidate for growing ordered self-assemblies on insulating surfaces.

\section{Experimental method and Density functional calculations}

The deposit of BDBA molecules on $\mathrm{KCl}(001)$ as well as the nc-AFM imaging of the resulting structures has been carried out in UHV at room temperature. The UHV setup includes two interconnected chambers for sample preparation and analysis with a base pressure of $4.10^{-10} \mathrm{mbar}$. The $\mathrm{KCl}(001)$ crystal was cleaved in air and annealed to $230{ }^{\circ} \mathrm{C}$ under UHV during one hour to remove impurities, evacuate residual charges whilst forming extended terraces. The BDBA molecules were purchased from Aldrich and thoroughly degassed in UHV prior to sublimation. They were sublimated from a home-made pyrolitic boron nitrate crucible at $130{ }^{\circ} \mathrm{C}$ on the substrate held at 
room temperature. During the sublimation, the pressure was maintained in the high- $10^{-9}$ mbar range. The molecular deposition rate was controlled by a quartz crystal microbalance and the rate was cross-checked by the nc-AFM images. Images were typically acquired half an hour after the deposit of the molecules on the surface and the sets of experiments lasted a few hours. Nc-AFM experiments were performed using a modified Omicron VT-AFM driven by a RHK electronics. The beam light used for the optical detection is supplied by a super-luminescent diode (Superlum SLD371, $\lambda=844 \mathrm{~nm}$, output power: $1 \mathrm{~mW}$ ). A N-doped silicon cantilever (PPP-NCl-50 NanoSensors with eigenfrequency $f_{0}=156.540 \mathrm{kHz}$, quality factor $Q=39000$ and stiffness $k=30 \mathrm{~N} / \mathrm{m}$ ) was used. The cantilever tip was solely heated in vacuum prior to experiments up to $120^{\circ} \mathrm{C}$ for $3 \mathrm{~h}$ to remove contaminations. The oscillation amplitude of the cantilever was $A_{0}=9.2 \mathrm{~nm}$ peak, calibrated with the constant- $\gamma$ method. ${ }^{49}$ The RHK software was used for the image processing.

Electronic structure calculations were performed within the framework of the density functional theory (DFT) using the generalized gradient approximation (GGA) parameterization by Perdew-Burke-Ernzerhof (PBE) ${ }^{50}$ for the exchange-correlation energy. The projector-augmented wave (PAW) method was used. ${ }^{51}$ In this method, the full wave functions and densities are expanded on a plane wave basis set without shape approximation. The core electrons are treated within the frozen-core approximation. Band structure calculations were carried out with a plane wave cutoff of $40 \mathrm{Ry}$. In these calculations, atomic positions were relaxed using the Lagrangian approach of Car and Parrinello. ${ }^{52}$ The two-dimensional structure of BDBA molecules was studied and optimized neglecting interactions between the molecules and the surface.

\section{Results and Discussion}

At low coverage, small molecular islands nucleate along step edges (data not shown) as was also observed with other molecules on ionic surfaces. ${ }^{21}$ For a coverage yielding about a monolayer (ML), extended two-dimensional islands have grown on terraces up to the almost complete ML. Images are reported in Scheme 2. For instance, Scheme 2a reveals that more than $85 \%$ of the 
$\mathrm{KCl}$ surface is covered by molecules. The islands extend over several hundreds of nanometers and exhibit straight edges, which shows that they are highly ordered and makes them discernable from the irregular $\mathrm{KCl}$ steps edges including kink sites. The molecular layers spread over the $\mathrm{KCl}$ steps and may overlay each other. In the inset shown in Scheme 2b, three BDBA layers are visible and labelled as 1, 2 and 3, respectively. Performing accurate heights measurements in nc-AFM requires careful analysis, particularly on heterogeneous samples as here. The topographical nc-AFM image is an "iso-frequency shift" $(\Delta f)$ map of the surface, i.e. also an "iso-force" map considering that the $\Delta f$ results from the averaged tip-surface interaction force over the oscillation cycles of the tip. When the imaging mechanism relies on short-range forces, height measurements are reliable from site to site. Conversely, if heterogeneous long-range electrostatic forces occur between the tip and the surface from site to site, then the apparent height of the object (step edge, molecular layer) will be influenced. ${ }^{53}$ The latter forces may occur owing to the presence of trapped charges at the tip apex and/or at the surface and, in most cases, owing to contact potential difference (CPD) between the tip and the surface. Heterogeneous samples such as organic layers on a substrate may be subject to such CPD changes. ${ }^{15,23,26,54}$ Then, it is mandatory to compensate the CPD by applying the proper DC bias to the tip and thus nullify the long-range electrostatic interaction. In order to estimate the height of the BDBA layers with respect to the substrate accurately, the tip-surface CPD has been measured before and after the deposit of the molecules. However with the tip used, no significant CPD was put in evidence owing to the presence of the molecules on the surface. Therefore, it is inferred that the heights measurements discussed below are not significantly affected by heterogeneous long-range electrostatic interactions. The cross-section $C$ shown in Scheme $2 \mathrm{~b}$ and Scheme $2 \mathrm{c}$ reveals similar apparent heights $h=(0.35 \pm 0.05) \mathrm{nm}$ between the first (on top of the substrate) and the second (on top of the first ML) molecular layers. This value is compliant with the inter-sheets separation derived from the triclinic structure of the molecular crystal $(0.37 \mathrm{~nm})$. Besides, the measured apparent heights are close to the $\mathrm{KCl}$ step height, $s=0.315 \mathrm{~nm}$. The cross-section $D$ shown in Scheme $2 \mathrm{~b}$ and Scheme $2 \mathrm{~d}$ reveals a height difference $\delta=(40 \pm 20) \mathrm{pm}$ between two MLs on the lower $\mathrm{KCl}$ terrace (left-hand side, labelled as 2) and the single one on the 
upper terrace (right-hand side, labelled as 1). This is consistent with the expected height $\delta^{\prime}$ given by: $s+h+\delta^{\prime}=2 h$, i.e. $\delta^{\prime}=h-s=35 \mathrm{pm}$. This suggests the structure of the first ML is quite similar to the one of the upper layers, these being more representative of the 3D structure of the molecular crystal.

In Scheme 3a and Scheme 3b, nc-AFM images reveal the atomic resolution on the $\mathrm{KCl}(001)$ substrate and the detailed structure of BDBA islands at the same time. This is a key aspect when performing the quantitative analysis of the molecular structure in nc-AFM. Firstly, this states that the two areas are imaged in a regime of short-range interactions for which tiny variations of the interaction forces are discernable. Hence, despite the local heterogeneity of the surface, no significant difference in the background interaction forces (vdW and ES) occur. This statement is also consistent with the experimental observation that no CPD change is observed owing to the presence of the molecules. Secondly, because the symmetry and the size of the unit cell of the substrate are unambiguously known, experimental images can be corrected from the lateral drift and creep of the scanner. Thus, the parameters of the molecular network can be derived with a high precision as well. In Scheme 3a and Scheme 3b, BDBA molecules are adsorbed close to a $\mathrm{KCl}$ step and on a terrace, respectively. In both cases, the network is made of an arrangement of dense molecular rows (see large arrow within each figure), rotated by an azimuthal angle $\pm \alpha=( \pm 27 \pm 2)^{\circ}$ between the direction of the dense rows (vector $\vec{a}$ ) and the [110] axis of the $\mathrm{KCl}$ substrate, as shown in the figures. This observation confirms the large scale images. The molecular network nucleates at step edges and then extends over the $\mathrm{KCl}$ terraces, while keeping the same structure. The value of $\alpha$ was confirmed on different areas. But despite this, no obvious epitaxy between the molecular layer and the substrate has been put in evidence, neither experimentally, nor with schematic representations based on the experimental parameters of the molecular lattice (see hereafter). We do not exclude an epitaxial ordering though, because of the following reasons. First, it is known that some molecular films can achieve epitaxial ordering that is not necessarily commensurate with the substrate, i.e. not with a point-on-point coincidence. ${ }^{55}$ Next, among alkali metals, potassium ions exhibit a clear preference to develop cation- $\pi$ interactions. ${ }^{56}$ Thus, they might interact with 
the benzene rings of the molecules. At last, the boron atoms, being electropositive, might interact with the chlorine ions of the substrate because the intramolecular B-B distance $(6.02 \AA)$ is compliant with the $\mathrm{Cl}-\mathrm{Cl}$ distance in the $\mathrm{KCl}$ crystal $(6.29 \AA)$. Therefore, owing to our experimental error bars, it cannot be inferred that the BDBA layer is incommensurate with respect to the $\mathrm{KCl}$ substrate, but rather claim that the epitaxial ordering, if any, is not obvious. Furthermore, if an epitaxial ordering occurs, then it is likely driven by the manner the first molecules adsorb at the step edges. This issue is currently being addressed by means of DFT calculations, which is out of the scope of the current work. Nevertheless, the experimental findings suggest that the interaction driving the adsorption between the molecular layer and the substrate has a weak character.

Scheme $3 \mathrm{c}$ is a high-resolution image of the BDBA network wherein individual molecules forming the parallel molecular rows are visible. The vertical contrast of the image is $30 \mathrm{pm}$. Four sketched molecules have been overlayed. For the sake of clarity, the bright spots have arbitrarily been assigned to the central part of each molecule. This issue will be addressed further hereafter. Molecules are imaged with a $9 \AA$ A-long and $4 \AA$-wide elliptical shape. The network has a rectangular unit cell with $\|\vec{a}\|=(5.2 \pm 0.2) \AA,\|\vec{b}\|=(10.0 \pm 0.2) \AA$ and $(\widehat{\vec{a}, \vec{b}})=(90 \pm 2)^{\circ}$. Do note that the $\vec{b}$ axis of the 2D network differs from the one of the triclinic unit cell: $\vec{b}_{2 D}=\vec{c}_{\text {tricl. }}-\vec{b}_{\text {tricl. }}$ Unless specified otherwise, $\vec{b}$ will refer to the axis of the $2 \mathrm{D}$ network in the following. The unit cell of the network consists of a single molecule, hence yielding a compacity of 1.9 molecule.nm ${ }^{-2}$. The lattice parameters have been determined by cross-comparison between direct measurements performed over several nc-AFM images and by 2D-Fourier transform of the latter images (see inset in Scheme 3c). Subsequent annealing of the structure at $100^{\circ} \mathrm{C}$ leads to the complete desorption of the molecules from the surface.

Consistently with the calculated structure of the BDBA molecule (Scheme 1a), the intermolecular distance between adjacent BDBA rows $(\|\vec{b}\|=10.0 \AA)$ suggests the formation of a pair of O-H...O hydrogen bonds between the boronic acid groups at both ends of the molecule, as shown in Scheme 4a and Scheme 4c. The corresponding distance between oxygen atoms is estimated to be (2.5 \pm 0.2$) \AA$, which is compliant with usual O-O distances within H-bonds involving OH groups. 
For instance, the calculated O-O distance between an acceptor water molecule and various $\mathrm{R}-\mathrm{OH}$ donor groups ranges between 2.49 and $3.22 \AA^{57}$ When dealing with H-bonds between $\mathrm{B}(\mathrm{OH})_{2}$ groups, DFT calculations predict that this distance yields $2.826 \AA{ }^{43}$ The intermolecular distance along the rows $(\|\vec{a}\|=5.2 \AA$ ) is also compliant with the formation of two equivalent O-H...O Hbonds $(\mathrm{O}-\mathrm{O}$ distance $=2.9 \pm 0.2 \AA)$. However, the rather short intermolecular distance along this direction prevents the molecules from being adsorbed in a flat lying configuration on the substrate. Indeed, a planar adsorption of the tectons would impose a significant steric hindrance between the aromatic cycles of the molecules (Scheme 4a and Scheme 4c). In order to lower the intermolecular steric hindrance and to favor the developments of strong H-bonds, it is inferred that the molecule adapts its conformation by tilting its phenylene cycle, while keeping the in-plane orientation of the $\mathrm{B}(\mathrm{OH})_{2}$ groups, as shown in Scheme $4 \mathrm{~b}$. The conformational adaptation of molecules within a supramolecular phase has been reported with oxalic amides on $\mathrm{Au}(111)^{58}$ and with tetrahydroxyquinones on $\mathrm{Ag}(111) .{ }^{59}$ Following these ideas, Scheme $4 \mathrm{~d}$ depicts the postulated BDBA network when considering an arbitrary tilt of the aromatic cycle. Thus, a H-bonded driven supramolecular self-assembly of BDBA can be grown with a single molecule per unit cell and developing two H-bonds along the axes $\vec{a}$ and $\vec{b}$. Furthermore, it is now important to point out that the molecular film acquires an intrinsic corrugation along axes $\vec{a}$ and $\vec{b}$ with the phenylene cycles protruding out of the mean plane of the $\mathrm{B}(\mathrm{OH})_{2}$ groups. This is the main reason why the bright spots have been assigned to the central part of the molecule in Scheme 3c.

To investigate the relevance of the postulated 2D structural model and to estimate its cohesion energy, DFT calculations have been carried out. These do not include the description of the $\mathrm{KCl}(001)$ surface. The most stable 2D structure of the molecular network is reported in Scheme 5a. The unit cell is composed of a single molecule and has a rectangular structure with calculated parameters $\left\|\vec{a}_{0}\right\|=4.998 \AA$ and $\left\|\vec{b}_{0}\right\|=10.178 \AA$, in very good agreement with the experimental observations. The calculated electron density within the plane of the $\mathrm{B}(\mathrm{OH})_{2}$ groups has been reported. The molecules develop primary H-bonds along $\vec{b}$ and secondary H-bonds to form rows along the $\vec{a}$ axis, which allows for the 2D growth of the molecular structure. The topological anal- 
ysis of the electron density at the saddle points where primary and secondary H-bonds are formed shows that they have the same strength. Besides, the calculations validate the required conformational adaptation of the molecule to form the structure. The calculated tilt of the phenylene cycle with respect to the $\mathrm{B}(\mathrm{OH})_{2}$ plane yields $38.2^{\circ}$ and prevents $\pi$ - $\pi$ interactions between aromatic cycles from occurring, as shown with the lower electron density between them. The calculated cohesion energy of the structure yields $0.95 \mathrm{eV}$ per molecule $(22 \mathrm{kcal} / \mathrm{mol})$, i.e. $\simeq 0.24 \mathrm{eV}$ per H-bond $(5.5 \mathrm{kcal} / \mathrm{mol})$. Following Steiner's classification, ${ }^{57}$ this value sorts them out as "mediumstrength" H-bonds. Nevertheless, the cohesion energy of the structure is comparable to other $\mathrm{H}$ bonded supramolecular phases on metals, such as HHTP on $\operatorname{Ag}(111) .^{7}$ Note also that the latter value is compliant with the strength of the H-bonds involved in the discrete phenylboronic acid homodimer of the gas phase, as determined by ab inito calculations $(0.28 \mathrm{eV}$ per H-bond, i.e. $6.45 \mathrm{kcal} / \mathrm{mol})^{43}$

Although the calculations are performed without the description of the substrate, the stability of the structure upon varying the size of the unit cell has been estimated with the goal to assess if it would be favorable for it to accommodate to the substrate. The experimental unit cell along axes $\vec{a}$ and $\vec{b}(\|\vec{a}\|=5.2 \AA$ and $\|\vec{b}\|=10.0 \AA)$ merely differs from the theoretical unit cell $\left(\left\|\overrightarrow{a_{0}}\right\|=\right.$ $4.998 \AA$ and $\left\|\overrightarrow{b_{0}}\right\|=10.178 \AA$ ) by $4 \%$ and $2 \%$, respectively. The calculated cohesion energies of the structure for various ratios of $a / a_{0}$ and $b / b_{0}$ are reported in Scheme $4 \mathrm{~b}$ and Scheme $4 \mathrm{c}$, respectively. As can be seen, the values of $a_{0}$ and $b_{0}$ correspond to a strong energy minimum. Any attempt to change the lattice parameters, for instance in order to accommodate the molecular layer to the substrate, would cost a significant energy. This suggests that the growth of the molecular network is not significantly influenced by the substrate. This might also explain the relatively low desorption temperature observed for this phase, despite the rather large intermolecular cohesion energy.

Finally, we have compared the combined experimental and theoretical results to the known structure of the bulk BDBA crystal reported by Cuamatzi et al. and calculated in DFT (Scheme 1b). As mentioned above, the crystal has a triclinic unit cell and consists of molecular sheets stacking 
along the $\vec{c}$ axis. A close inspection to the structure of a $2 \mathrm{D}$ sheet shows that the molecules are arranged therein with an almost equivalent structure to ours. In particular, Cuamatzi et al. state that the plane of the phenylene group is twisted out of the mean plane of the $\mathrm{B}(\mathrm{OH})_{2}$ groups by approximately $35^{\circ}$, which is confirmed by the DFT calculations. Therefore the observed supramolecular phase of BDBA on $\mathrm{KCl}(001)$ is ultimately almost similar to a single $2 \mathrm{D}$ sheet of the molecular crystal. This unambiguously states that the interaction with the substrate is weak and does not influence notably the molecular network.

\section{Conclusion}

A joint experimental and theoretical structural analysis of the molecular network of 1,4-benzene diboronic acid molecules on $\mathrm{KCl}(001)$ at room temperature has been presented. The network consists of an extended 2D supramolecular phase driven by H-bonds with a cohesion energy of $0.95 \mathrm{eV} /$ molecule. The structure requires conformational adaptation of the molecules. They do so by twisting their phenylene cycle out of the plane of the diboronic acids functions, which reduces the intermolecular steric hindrance while strengthening $\mathrm{H}$-bonds along the axes forming the unit cell of the structure. Such an unusually large cohesion energy for a molecular network on a bulk insulator mainly originates from the H-bonded intermolecular interactions as the experimental findings show that the molecular film weakly interacts with the substrate. Tailoring the moleculesubstrate interaction whilst preserving strong intermolecular interactions might be a path towards highly robust molecular assemblies on bulk insulators.

\section{Acknowledgement}

The authors would like to thank Mathieu Abel, Sylvain Clair and Mireille Mossoyan for stimulating discussions and acknowledge financial support of the Centre National de la Recherche Scientifique and of the Région Provence Alpes Côtes-d'Azur. 


\section{References}

(1) Barth, J. Ann. Rev. Phys. Chem. 2007, 58, 375-407.

(2) Elemans, J.; Lei, S.; Feyter, S. D. Angew. Chem. Int. Ed. 2009, 48, 7298-7332.

(3) Lehn, J.-M. Supramolecular Chemistry-Concepts and Perspectives; Wiley-VCH, 1995.

(4) Lehn, J.-M. Science 2002, 295, 2400.

(5) Dmitriev, A.; Lin, N.; Weckesser, J.; Barth, J.; Kern, K. J. Phys. Chem. B 2002, 106, 69076912.

(6) Canas-Ventura, M.; Klappenberger, F.; Clair, S.; Pons, S.; Kern, K.; Brune, H.; Strunskus, T.; Wöll, C.; Fasel, R.; Barth, J. J. Chem. Phys. 2006, 125, 184710.

(7) Pawlak, R.; Clair, S.; Oison, V.; Abel, M.; Ourdjini, O.; Zwaneveld, N.; Gigmes, D.; Bertin, D.; Nony, L.; L.Porte, ChemPhysChem 2009, 10, 1032-1035.

(8) Sakaguchi, H.; Matsumura, H.; Gong, H.; Abouelwafa, A. Science 2005, 310, 1002 - 1006.

(9) Zwaneveld, N.; Pawlak, R.; Abel, M.; Catalin, D.; Gigmes, D.; Bertin, D.; Porte, L. Journal of American Chemical Society 2008, 130, 6678-6679.

(10) Matena, M.; Riehm, T.; Stöhr, M.; Jung, T.; Gade, L. Angew. Chem. Int. Ed. 2008, 47, 24142417.

(11) Veld, M. I.; Iavicoli, P.; Haq, S.; Amabilino, D.; Raval, R. Chem. Commun. 2008, 1536-1538.

(12) Weigelt, S.; Busse, C.; Bombis, C.; Knudsen, M.; Gothelf, K.; Lægsgaard, E.; Besenbacher, F.; Linderoth, T. Angew. Chem. Int. Ed. 2008, 120, 4478-4482.

(13) Treier, M.; Richardson, N.; Fasel, R. J. Am. Chem. Soc. 2008, 130, 14054-14055.

(14) Dienel, T.; Loppacher, C.; Mannsfeld, S.; Forker, R.; Fritz, T. Advanced Materials 2008, 20, 959. 
(15) Burke, S.; LeDue, J.; Miyahara, Y.; Topple, J.; Fostner, S.; Grütter, P. Nanotechnology 2009, $20,264012$.

(16) Qiu, X.; Nazin, G.; Ho, W. Science 2003, 299, 542-546.

(17) Repp, J.; Meyer, G. Phys. Rev. Lett. 2005, 94, 026803.

(18) Koch, N.; Duhm, S.; Rabe, J.; Vollmer, A.; Johnson, R. Phys. Rev. Lett. 2005, 95, 237601.

(19) Forker, R.; Kasemann, D.; Dienel, T.; Wagner, C.; Franke, R.; Müllen, K.; Fritz, T. Adv. Mat. 2008, 20, 4450-4454.

(20) Bombis, C.; Kalashnyk, N.; Xu, W.; Lægsgaard, E.; Besenbacher, F.; Linderoth, T. Small 2009, 5, 2177-2182.

(21) Nony, L.; Bennewitz, R.; Pfeiffer, O.; Gnecco, E.; Baratoff, A.; Meyer, E.; Eguchi, T.; Gourdon, A.; Joachim, C. Nanotechnology 2004, 15, S91-S96.

(22) Kunstmann, T.; Schlarb, A.; Fendrich, M.; Wagner, T.; Mölller, R.; Hoffmann, R. Phys. Rev. B 2005, 71, 121403(R).

(23) Loppacher, C.; Zerweck, U.; Eng, L.; Gemming, S.; Seifert, G.; Olbrich, C.; Morawetz, K.; Schreiber, M. Nanotechnology 2006, 17, 1568-1573.

(24) Mativetsky, J.; Burke, S.; Fostner, S.; Grütter, P. Small 2007, 3, 818-821.

(25) Fendrich, M.; Kunstmann, T.; Paulkowski, D.; Möller, R. Nanotechnology 2007, 18, 084004.

(26) Burke, S.; Ji, W.; Mativetsky, J.; Topple, J.; Fostner, S.; Gao, H.-J.; Guo, H.; Grütter, P. Phys. Rev. Lett. 2008, 100, 186104.

(27) Burke, S.; Topple, J.; Grütter, P. J. Phys.: Condens. Matter 2009, 21, 423101.

(28) Fendrich, M.; Kunstmann, T. Appl. Phys. Lett. 2007, 91, 023101. 
(29) Fendrich, M.; Lange, M.; Weiss, C.; Kunstmann, T.; Möller, R. J. Appl. Phys. 2009, 105, 094311.

(30) Burke, S.; Mativetsky, J.; Hoffmann, R.; Grütter, P. Phys. Rev. Lett. 2005, 94, 096102.

(31) Burke, S. A.; Mativetsky, J. M.; Fostner, S.; Grütter, P. Phys. Rev. B 2007, 76, 035419.

(32) Loske, F.; Bechstein, R.; Schütte, J.; Ostendorf, F.; Reichling, M.; Kühnle, A. Nanotechnology 2009, 20, 065606.

(33) Maier, S.; Fendt, L.-A.; Zimmerli, L.; Glatzel, T.; Pfeiffer, O.; Diederich, F.; Meyer, E. Small 2008, 4, 1115-1118.

(34) Glatzel, T.; Zimmerl, L.; Koch, S.; Kawai, S.; Meyer, E. Appl. Phys. Lett. 2009, 94, 063303.

(35) Kawai, S.; Maier, S.; Glatzel, T.; Koch, S.; Such, B.; Zimmerli, L.; Fendt, L.-A.; Diederich, F.; Meyer, E. Appl. Phys. Lett. 2009, 95, 103109.

(36) Nony, L.; Gnecco, E.; Baratoff, A.; Alkauskas, A.; Bennewitz, R.; Pfeiffer, O.; Maier, S.; Wetzel, A.; Meyer, E.; Gerber, C. Nano Lett. 2004, 4, 2185-2189.

(37) These values are derived from molecular mechanism calculations for the $\mathrm{p} 3 \mathrm{x} 3$ phase of PTCDA on $\mathrm{NaCl}(001)$, as reported in the supporting information for ref.. ${ }^{27}$

(38) Hall, D. G. Boronic Acids: Preparation, Applications in Organic Synthesis and Medicine; Wiley-VCH: Germany, 2005.

(39) Rodriguez-Cuamatzi, P.; Luna-Garcia, R.; Torres-Huerta, A.; Bernal-Uruchurtu, M.; Barba, V.; Höpfl, H. Cryst. Growth Design 2009, 9, 1575-1583.

(40) Li, Y.; Liu, Y.; Bu, W.; Guo, J.; Wang, Y. Chem. Commun. 2000, 1551-1552.

(41) Lamère, J.; Lacroix, P.; Farfan, N.; Rivera, J.; Santillan, R.; Nakatani, K. J. Mater. Chem. 2006, 16, 2913-2920. 
(42) Rodriguez-Cuamatzi, P.; Vargas-Diaz, G.; Maris, T.; Wuest, J.; Höpfl, H. Acta Cryst. 2004, E60, o1315-o1317.

(43) Rodriguez-Cuamatzi, P.; Arillo-Flores, O.; Bernal-Uruchurtu, M.; Höpfl, H. Cryst. Growth Design 2005, 5, 167-175.

(44) Maly, K.; Maris, T.; Wuest, J. CrystEngComm 2006, 8, 33-35.

(45) Maly, K.; Malek, N.; Fournier, J.-H.; Rodriguez-Cuamatzi, P.; Maris, T.; Wuest, J. Pure Appl. Chem. 2006, 7, 1305-1321.

(46) Côté, A.; Benin, A.; Ockwig, N.; O’Keeffe, M.; Matzger, A.; Yaghi, O. Science 2005, 310, 1166-1170.

(47) Côté, A.; El-Kaderi, H.; Furukawa, H.; Hunt, J.; Yaghi, O. J. Am. Chem. Soc. 2007, 129, $12914-12915$.

(48) Sassi, M.; Oison, V.; Debierre, J.-M.; Humbel, S. ChemPhysChem 2009, 10, 2480-2485.

(49) Giessibl, F.; Bielefeldt, H. Phys. Rev. B 2000, 61, 9968.

(50) Perdew, J.; Burke, K.; Ernzerhof, M. Phys. Rev. Lett. 1996, 77, 3865-3868.

(51) Blöchl, P. Phys. Rev. B 1994, 50, 17953.

(52) Car, R.; Parrinello, M. Phys. Rev. Lett. 1985, 55, 2471.

(53) Sadewasser, S.; Lux-Steiner, M. Phys. Rev. Lett. 2003, 91, 266101.

(54) Zerweck, U.; Loppacher, C.; Otto, T.; Grafström, S.; Eng, L. Nanotechnology 2007, 18, 084006.

(55) Hooks, D.; Fritz, T.; Ward, M. Adv. Mat. 2001, 13, 227-241.

(56) Reyes-Martinez, R.; Höpfl, H.; Godoy-Alcantar, C.; Medrano, F.; Tlahuext, H. CrystEngComm 2009, 11, 2417. 
(57) Steiner, T. Angew. Chem. Int. Ed. 2002, 41, 48-76.

(58) Klappenberger, F.; Canas-Ventura, M.; Clair, S.; Pons, S.; Schlickum, U.; Qu, Z.-R.; ; Brune, H.; Kern, K.; Strunskus, T.; Wöll, C.; Comisso, A.; Vita, A. D.; Ruben, M.; Barth, J. ChemPhysChem 2007, 8, 1782-1786.

(59) Abel, M.; Oison, V.; Koudia, M.; Porte, L. Phys. Rev. B 2008, 77, 085410. 


\section{Figures}

a)

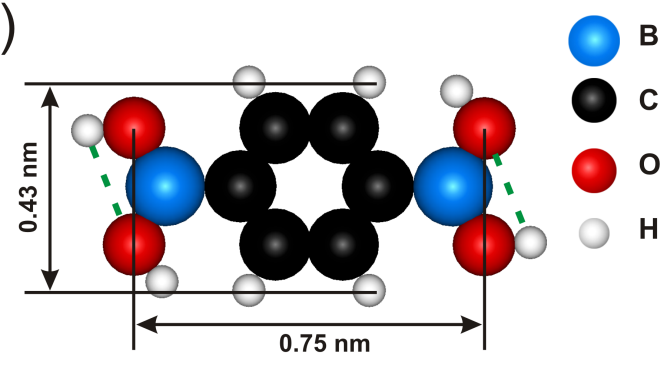

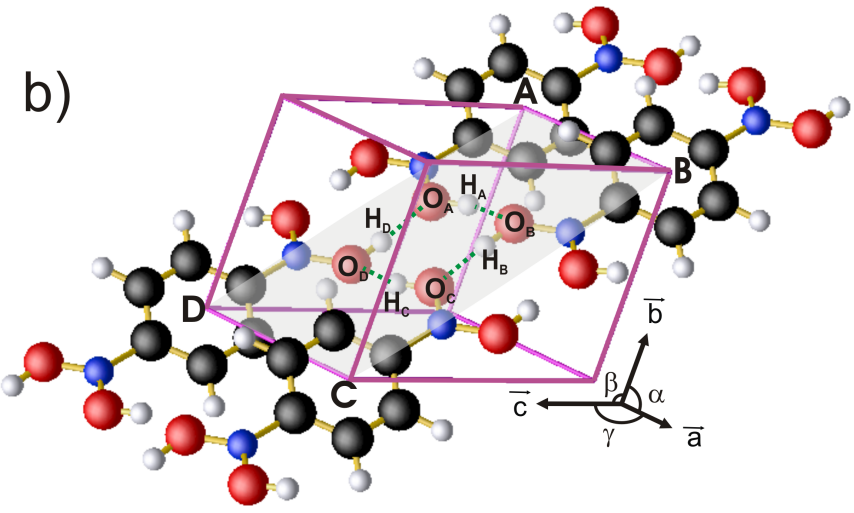

Scheme 1: a- DFT calculation of the most stable configuration of the free standing BDBA molecule. The molecule has a planar configuration. Green doted lines show intramolecular hydrogen bonds. b- DFT calculation of the triclinic unit cell depicting the 3D molecular crystal. The parameters are given in the text. For the sake of clarity, only four molecules labelled as $A, B, C$ and $D$ of the unit cell have been sketched (among height). Intermolecular H-bonds are developed within the plane (a, c-b) (shaded area) to form 2D sheets. The volumic crystal results from the stacking of the sheets along the $\mathbf{c}$ axis. 

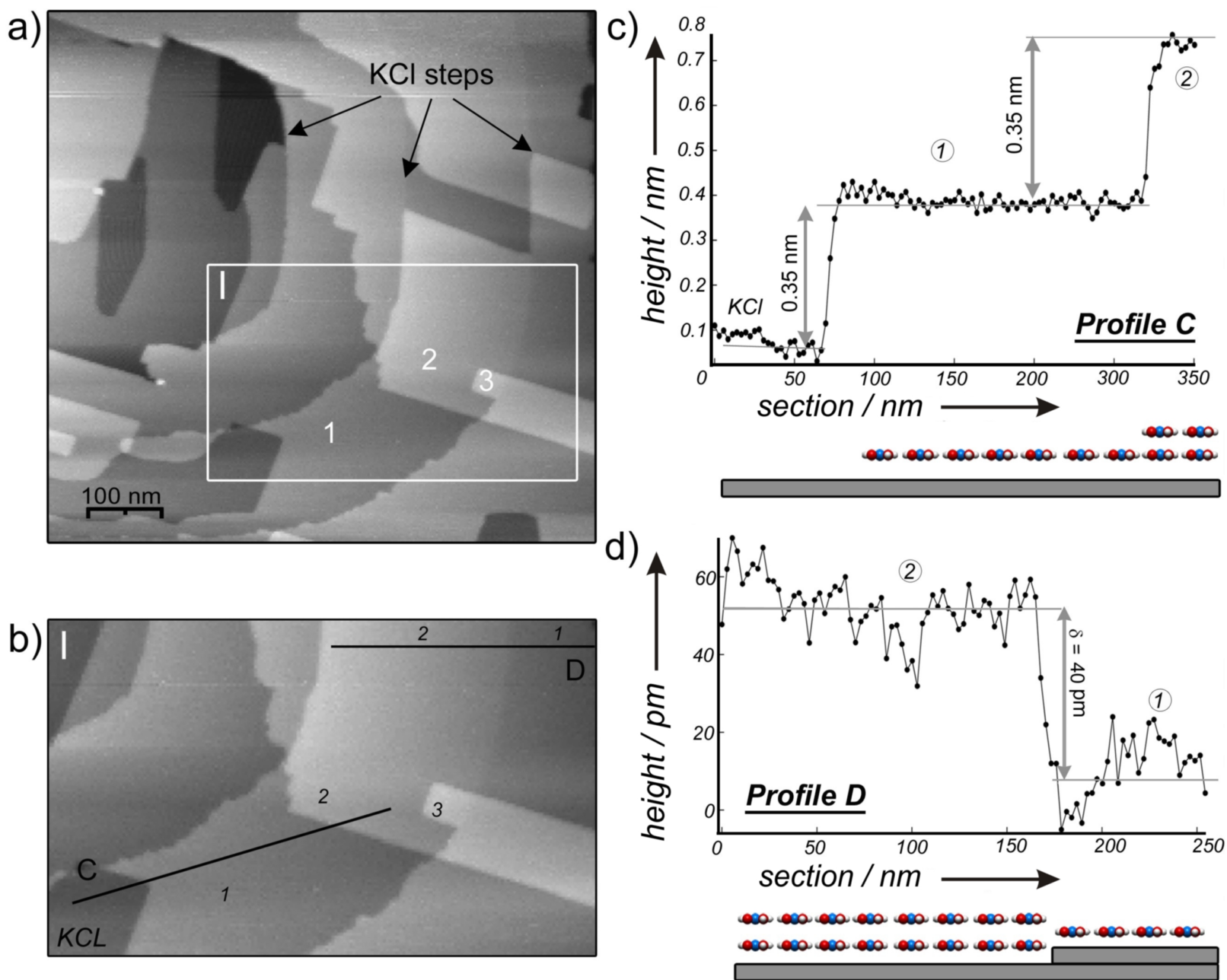

Scheme 2: a)- Nc-AFM image after deposition of $\simeq 1$ ML of BDBA $\left(700 \times 700 \mathrm{~nm}^{2}, \Delta f=-12 \mathrm{~Hz}\right)$. $\mathrm{Bare} \mathrm{KCl}$ areas, $\mathrm{KCl}$ steps, and overlaying BDBA layers are distinguishable. Locally, up to three layers may overlay each other (numbers 1, 2 and 3 in the inset). The inset is magnified in b). c) and d)- Cross sections C and D taken from the inset shown in b), respectively. For each of them, the surface configuration is sketched below. 


\section{a)}

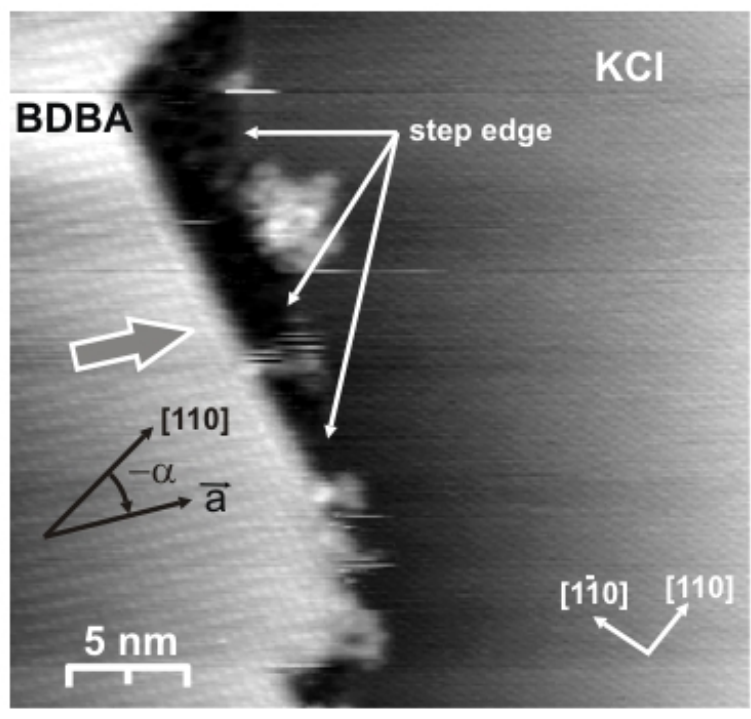

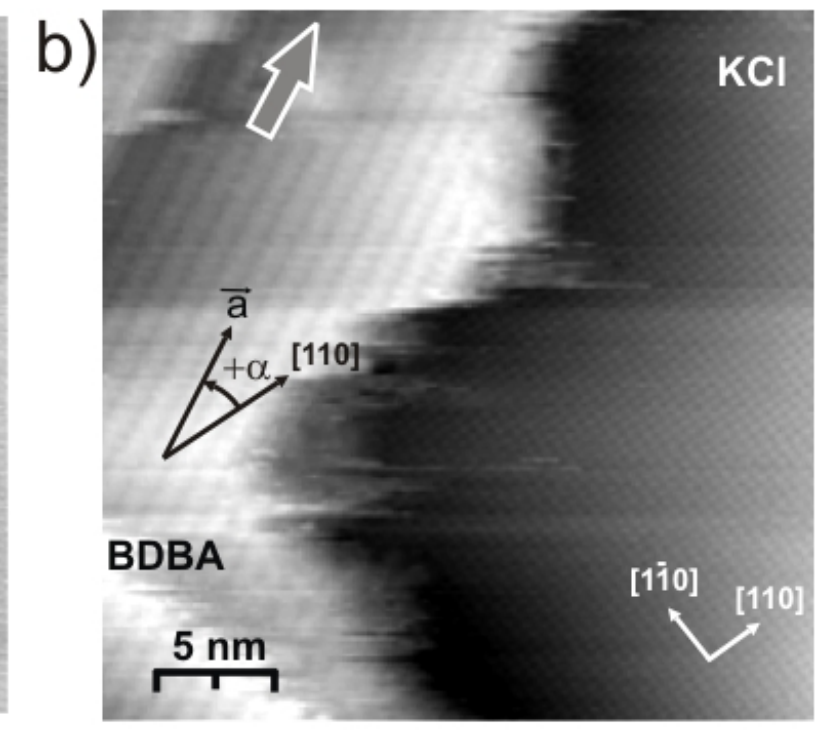

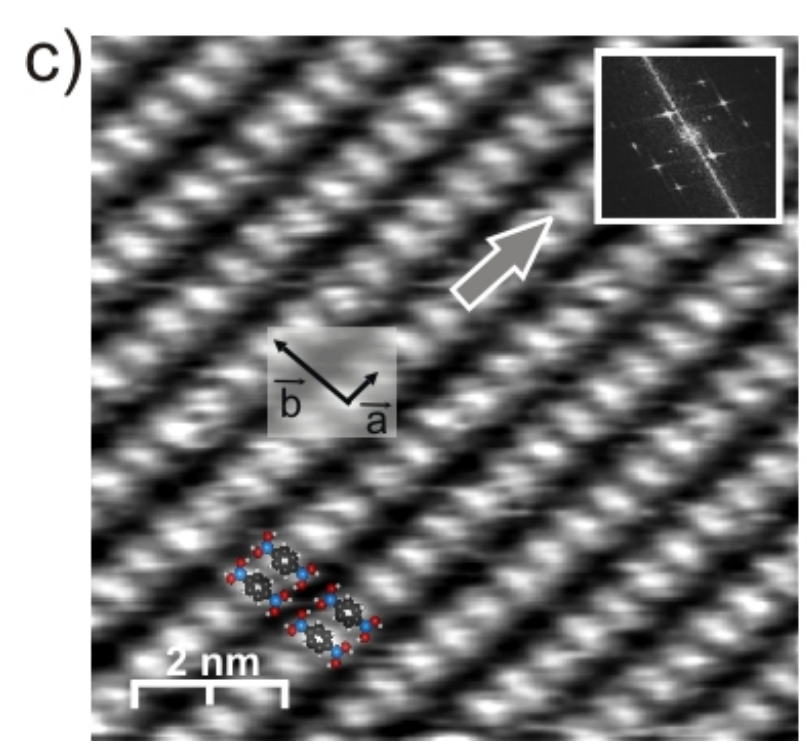

Scheme 3: a) and b) Nc-AFM images of the molecular network close to a $\mathrm{KCl}$ step and on a terrace, respectively. The network is made of dense molecular rows, the direction of which is sketched by a large grey arrow, parallel to each other. They are rotated by $\alpha=+27^{\circ}$ (a) and $-27^{\circ}$ (b) with respect to the [110] axis of the $\mathrm{KCl}$ substrate $\left(30 \times 30 \mathrm{~nm}^{2}, \Delta f=-12 \mathrm{~Hz}\right)$. c) High-resolution nc-AFM image of the BDBA rectangular network. The inset shows the 2D-Fourier transform of the molecular network $\left(9 \times 9 \mathrm{~nm}^{2}, \Delta f=-18 \mathrm{~Hz}\right)$. The derived parameters for the unit cell are $\|\vec{a}\|=$ $(5.2 \pm 0.2) \AA$ and $\|\vec{b}\|=(10.0 \pm 0.2) \AA$. Four molecules have been sketched to show the postulated molecular conformation. 
a)

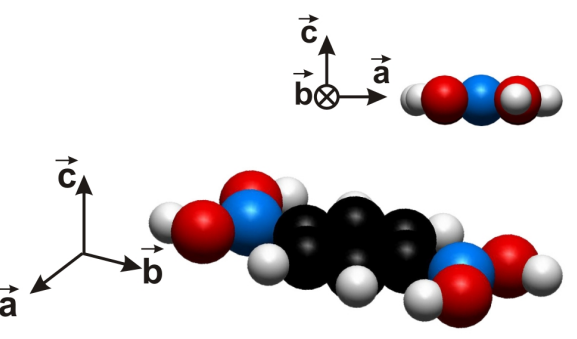

c)

Planar configuration

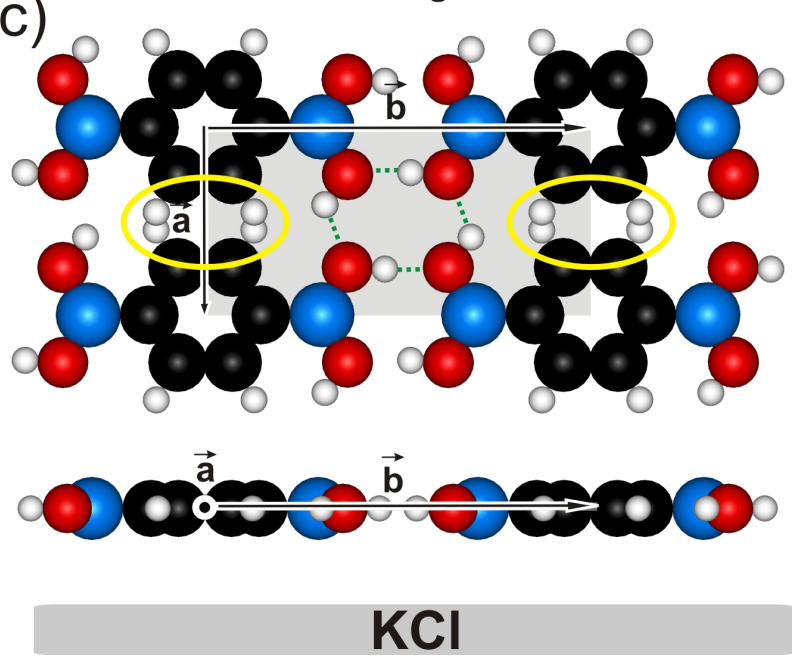

b)

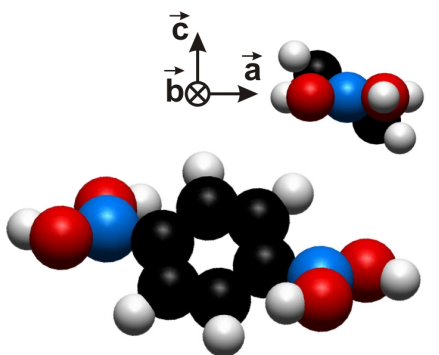

Tilted configuration
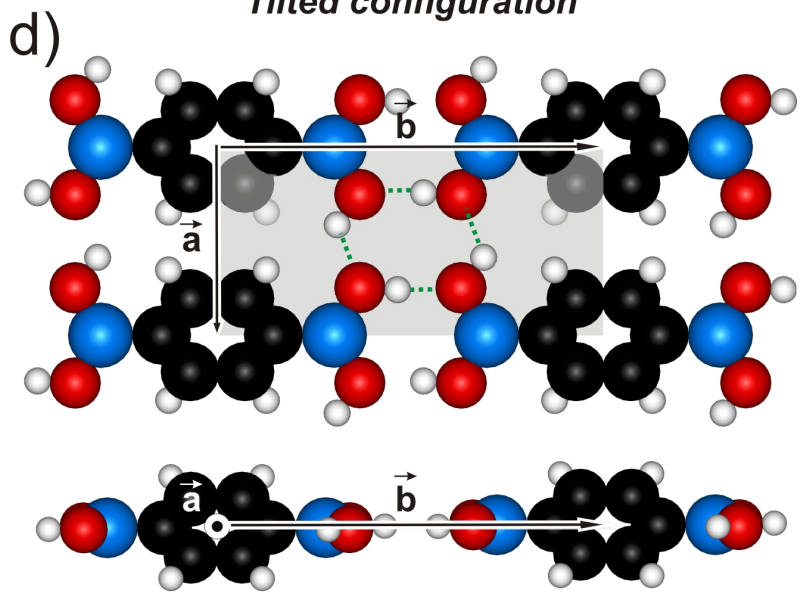

$\mathrm{KCl}$

Scheme 4: a) Planar conformation of BDBA as shown in Scheme 1a. b) Conformational adaptation of the molecule resulting in the tilt of the aromatic cycle out of the plane of diboronic acid functions. c) Structural model of the BDBA network on $\mathrm{KCl}(001)$ as measured experimentally assuming a planar configuration of individual tectons. The shaded area stands for the unit cell of the network. In this configuration, a significant intermolecular steric hindrance occurs (circles). d) Same as c- but considering the tilted conformation of the molecule. The steric hindrance is lowered, which allows for the development of four O-H...O hydrogen bonds (dotted lines) per molecule that are included within the mean plane of the $\mathrm{B}(\mathrm{OH})_{2}$ groups. 

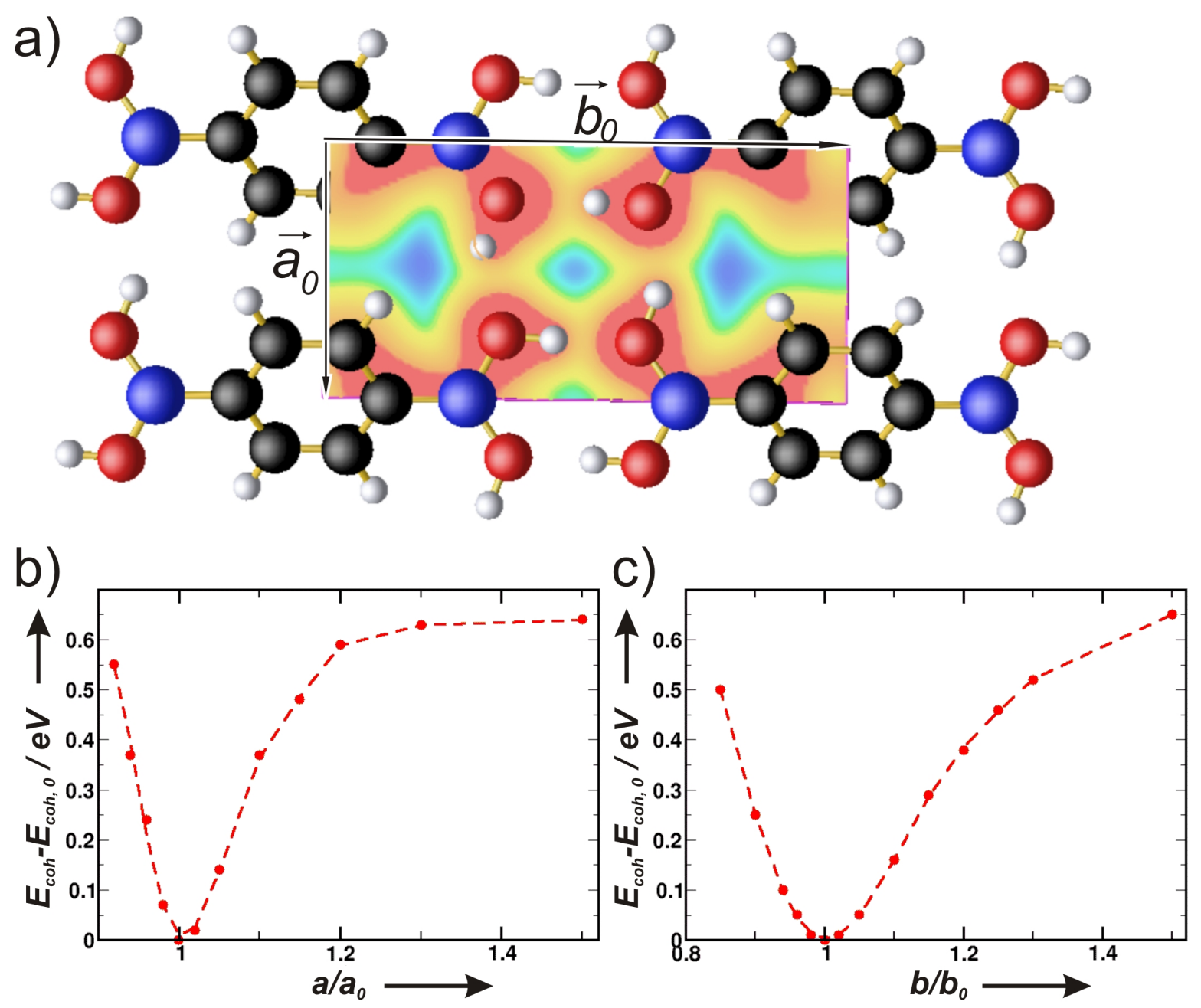

Scheme 5: a) Structure of the most stable unit cell computed by DFT without considering the substrate. The calculated cohesion energy is $E_{\text {coh, } 0}=0.95 \mathrm{eV} /$ molecule. The parameters are $\left\|\overrightarrow{a_{0}}\right\|=$ $4.998 \AA$ and $\left\|\overrightarrow{b_{0}}\right\|=10.178 \AA$, in excellent agreement with the experimental results. The total electron density has been reported in the plane of the $\mathrm{B}(\mathrm{OH})_{2}$ groups. The isodensity values increase from 0.01 (blue region) to 0.7 and higher (red region) electron per $\AA^{3}$. Saddle points corresponding to the formation of four equivalent $\mathrm{H}$-bonds are visible. The resulting structure derives from the conformational adaptation of the molecules. The cohesion energy of the unit cell as a function of the parameters along directions $\vec{a}$ and $\vec{b}$ is reported in b) and c), respectively. 